\title{
Suvorexant: An option for preventing delirium?
}

Saba Afshar, MBBS, Kathryn Marcellus, MD, and Rif S. El-Mallakh, MD

$\mathrm{D}$ elirium is characterized by a disturbance of consciousness or cognition that typically has a rapid onset and fluctuating course. ${ }^{1}$ Up to $42 \%$ of hospitalized geriatric patients experience delirium. ${ }^{1}$ Approximately $10 \%$ to $31 \%$ of these patients have the condition upon admission, and the remainder develop it during their hospitalization. ${ }^{1}$ Unfortunately, options for preventing or treating delirium are limited. Benzodiazepines and antipsychotic medications have been used to treat problematic behaviors associated with delirium, but they do not effectively reduce the occurrence, duration, or severity of this condition. ${ }^{2,3}$

Recent evidence suggests that suvorexant, which is FDA-approved for insomnia, may be useful for preventing delirium. Suvorexant-a dual orexin receptor (OX1R, OX2R) antagonist-promotes sleep onset and maintenance, and is associated with normal measures of sleep activity such as rapid eye movement (REM) sleep, nonREM sleep, and sleep stage-specific electroencephalographic profiles. ${ }^{4}$ Here we review 3 studies that evaluated suvorexant for preventing delirium.

Hatta et al. ${ }^{5}$ In this randomized, placebocontrolled, blinded, multicenter study, 72 patients (age 65 to 89 ) newly admitted to an ICU were randomized to suvorexant, $15 \mathrm{mg} / \mathrm{d},(\mathrm{n}=36)$ or placebo $(\mathrm{n}=36)$ for 3 days. ${ }^{5}$ None of the patients taking suvorexant developed delirium, whereas $17 \%$ (6 patients) in the placebo group did $(P=.025){ }^{5}$

Azuma et al. ${ }^{6}$ In this 7-day, blinded, randomized study of 70 adult patients (age
220) admitted to an ICU, 34 participants received suvorexant (15 $\mathrm{mg}$ nightly for age $<65,20 \mathrm{mg}$ nightly for age $\geq 65$ ) and the rest received treatment as usual (TAU). Suvorexant was associated with a lower incidence of delirium symptoms $(\mathrm{n}=6$, $17.6 \%)$ compared with TAU ( $\mathrm{n}=17,47.2 \%)$ $(P=.011) .{ }^{6}$ The onset of delirium was earlier in the TAU group $(P<.05){ }^{6}$

Hatta et al.7 In this large prospective, observational study of adults (age >65), 526 patients with significant risk factors for delirium were prescribed suvorexant and/or ramelteon. Approximately $16 \%$ of the patients who received either or both of these medications met DSM-5 criteria for delirium, compared with $24 \%$ who did not receive these medications $(P=.005)^{?}$

\section{Acknowledgment}

The authors thank Jakob Evans, BS, for compiling much of the research for this article.

\section{References}

1. Siddiqi N, House AO, Holmes JD. Occurrence and outcome of delirium in medical in-patients: a systematic literature review. Age Ageing. 2006;35(4):350-364

2. Lonergan E, Luxenberg J, Areosa Sastre A. Benzodiazepines for delirium. Cochrane Database Syst Rev. 2009;2009(4):CD006379.

3. Burry L, Mehta S, Perreault MM, et al. Antipsychotics for treatment of delirium in hospitalised non-ICU patients. Cochrane Database Syst Rev. 2018;6(6):CD005594.

4. Coleman PJ, Gotter AL, Herring WJ, et al. The discovery of suvorexant, the first orexin receptor drug for insomnia. Annu Rev Pharmacol Toxicol. 2017;57:509-533.

5. Hatta K, Kishi Y, Wada K, et al. Preventive effects of suvorexant on delirium: a randomized placebo-controlled trial. J Clin Psychiatry. 2017;78(8):e970-e979.

6. Azuma K, Takaesu Y, Soeda H, et al. Ability of suvorexant to prevent delirium in patients in the intensive care unit: a randomized controlled trial. Acute Med Surg. 2018;5(4): 362-368.

7. Hatta K, Kishi Y, Wada K, et al. Real-world effectiveness of ramelteon and suvorexant for delirium prevention in 948 patients with delirium risk factors. J Clin Psychiatry. 2019;81(1):19m12865. doi: 10.4088/JCP.19m12865
Dr. Afshar is a PGY-3 Psychiatric Resident, Department of Psychiatry and Behavioral Sciences, University of Louisville School of Medicine, Louisville, Kentucky. Dr. Marcellus is a PGY-2 Psychiatric Resident, Department of Psychiatry and Behavioral Sciences, University of Louisville School of Medicine, Louisville, Kentucky. Dr. El-Mallakh is Professor and Director, Mood Disorders Research Program, Department of Psychiatry and Behavioral Sciences, University of Louisville School of Medicine, Louisville, Kentucky. He is Section Editor for CURRENT Psychiatry's Clinical Neuroscience department.

Disclosures

Dr. El-Mallakh is a speaker for Alkermes, Eisai, Janssen, Indivior, Intra-Cellular Therapies, Lundbeck, Otsuka, Noven, and Teva. The other authors report no financial relationships with any companies whose products are mentioned in this article, or with manufacturers of competing products.

doi: $10.12788 / \mathrm{cp} .0084$

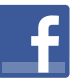

Discuss this article at www.facebook.com/ MDedgePsychiatry 